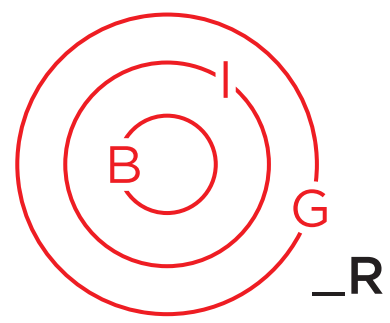

REVIEW ESSAY

\title{
New Grounds in Border Studies
}

Chiara Brambilla, Jussi Laine, James Scott, and Gianluca Bocchi (eds). Borderscaping: Imaginations and Practices of Border Making. Abingdon: Routledge, 2017

Matthew Longo. The Politics of Borders: Sovereignty, Security, and the Citizen after 9/11. Cambridge University Press, 2017.

Gerhard Besier and Katarzyna Stoklosa (eds.) How to Deal with Refugees? Europe as a Continent of Dreams. Zurich, Switzerland: LIT Verlag, 2018.

Anirudh Kala. The Unsafe Asylum: Stories of Partition and Madness. New Delhi, India: Speaking Tiger Publishing, 2018.

Aybike Açikel. A Prolonged Residency: Syrian Refugees' Crisis of Integration into Turkey, Istanbul. Turkey: Libra Kitap, 2018.

Nicola Mai. Mobile Orientations: An intimate Autoethnography of Migration, Sex Work and Humanitarian Borders. University of Chicago Press, 2018.
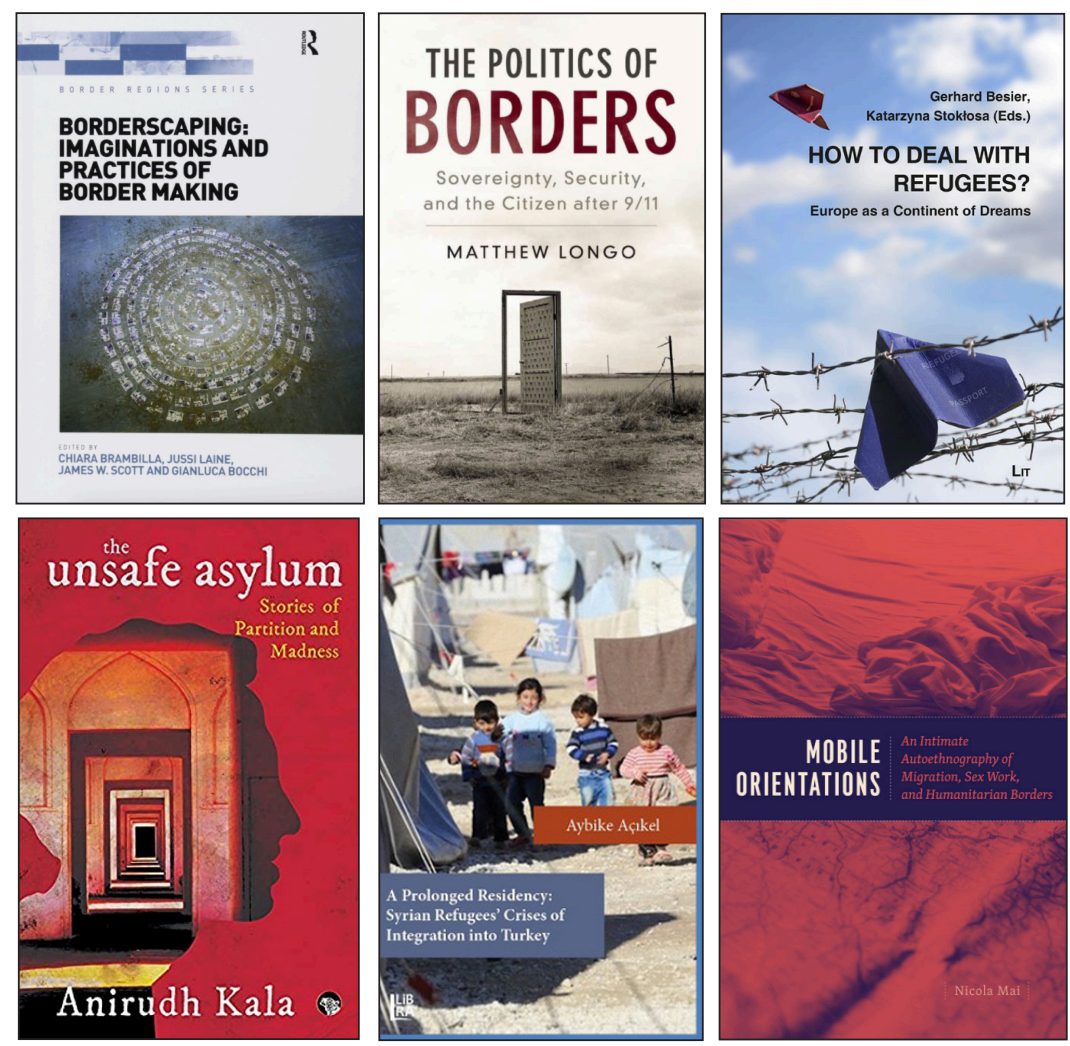

In the last few years border studies have expanded thematically and across disciplines. The field of border and borderland studies is now truly interdisciplinary, and numerous new books are published yearly. This review essay comments on six paperbacks: indeed, some of these are volumes that are re-issued, indicating the growing maturity of the field but also the greater expected distribution of border research. These were published during the academic years of 2017-18. I review them in an attempt to document some of the key debates that are emerging, and to a limited extent also, debates that are changing the discussions in border and borderland scholarship.

In 2014, Brambilla et. al., co-edited a beautiful volume called Borderscaping: Imaginations and practices of border making; I am reviewing here the second edition that came out in 2017 in paperback. A collection of twenty-two chapters, the book is organized in five sections that discuss borders from the perspective of borderscapes, a reference to the possibly uneasy demarcation of landscapes and thus particular negotiations between thinking borders

* Emmanuel Brunet-Jailly, PhD, is Chief Editor of Borders in Globalization Review and Professor of Public Administration at the University of Victoria, Canada. Contact: ebrunetj@uvic.ca 
and the processes of bordering and their application in various exemplary spaces: the southern European Mediterranean region, cities and their urban and rural manifestations in borderland regions, and the nature of thinking and seeing borders and borderscapes beyond space and territorialities across identity and art formations.

The front-end chapters are more conceptual. They discuss border imaginaries, power, resource and geo-graphies/representations. The core chapters focus on various illustrations of borderscapes in the media, museums, literary narratives or their social manifestations. They also look at aesthetic counter-hegemonic actions-these are rich chapters that contribute to expanding our thinking about borders well beyond the territorialist reference to boundary lines, and suggest many other instances of bordering that engage with social science, as well as literatures and other visual art forms-which often trespass spaces, or transgress ideas, emotions or indeed our imaginaries as well. They challenge established representations, visions of what a border reality is all about.

Brambilla's collection's primary contribution is that borders offer a distinct sensible perspective on power and space. Indeed, what borderscaping does is discuss with elegance the relativity of any boundary lines, or borders, to underscore the continuous construction and reconstruction of borders, the mobility and layered complexity of borderlands imaginaries, narratives and their multifaceted representations in, for instance, bordering minds and spaces well beyond international boundary lines. What Brambilla and her co-authors do not explore as much, however, is one aspect of border production, which emerges from the politics of borders.

Matthew Longo's The Politics of Borders, Sovereignty, Security and the Citizen after 9/11, drawn from his dissertation, is also a must. Indeed, while it is a catchy title for a book; it is a measured, primarily theoretical discussion grounded in limited but serious field work that broaches theoretical and contemplative thoughts on 21st century borders. Indeed, The Politics of Borders is primarily a politicalphilosophic reflection on borders (thick and thin). The book is organized around six chapters in two thematic sections: "The Perimeter" (with chapters exploring borders as walls, as meeting points of sovereignty, and in the context of empire), and "The Ports of Entry" (with chapters on big data, the politics of trust, and the future of security). The first part on the perimeter is very strong-please come in, let us tax you, and trade flow logics follow, suggesting our world of borders is very real but may be not just about states' territoriality. In the second part of the book, the Ports of Entry section is more speculative, joining shoulder to shoulder ideas around filtering data, management of data, and the decline of citizen privacy. States know about us already. There is profiling. It is done, and to a significant extent in some cases. The goals may be about profiling specific (risky) people but what this means is far from clear. The state is terrified because it understands what can be done, how data can change everything; hence the question is how do states manage data. China's Uighurs are not discussed here, but we have a sense of what those questions mean everywhere. This is not a dystopian discussion anymore: it confronts us today.

For Longo, the border is a place of definition and delineation, but also an in-between. The book draws from some field work but really is a discussion of political philosophy where the likes of Gloria Anzaldua, Salman Rushdie, Giorgo Agamben, Michel Foucault, Will Kimlicka, John Locke, Machiavelli, Jean Jacques Rousseau and James Tully provide the real material to be contended with. The questions raised in this book engage us with the tough "what are borders in the 21st century?" And, this is where the conclusion keeps us on our toes, summarily pointing to machines, perverting democratic institutions and values, and where the rule of law does not protect as it used to. This is a book that will stay and that all students should read and contend with-it is here to stay because it articulates a lot of issues most scholars studying borders contend with when they try to make sense of the data they collect in the variety of case studies we collectively work with. What I would have liked to read as well is more discussion of the concrete evidence that we already have of some of the issues, especially in part two of the book. It is a necessary remark because if we want to engage with policy makers we need people to be more and more aware of what, in empirical and quantitative terms, political philosopher Longo suggests.

This reader found The Unsafe Asylum by Anirudh Kala also an important contribution. This is a set of thirteen short fictional stories based on the psychiatric trauma witnessed by Dr. Kala, the former president of the Psychiatrist Society of India and Pakistan. Today, Dr. Kala heads the Department of Psychiatrics at the local hospital in Ludhiana, Punjab/Himachal Pradesh, India. Obviously, none of these stories are witness testaments of traceable individuals but they are the poignant results of years of psychiatric practice in a region where people still discuss their own experiences of the bleak year of 1947 when British India subdivided into two, then three, new and internationally recognized states, India and Pakistan, then Bangladesh (noticeably unknown though is that Punjab, then the largest state of British-India was consequently subdivided in four: Punjab in Pakistan, Punjab in India as well as Himachal Pradesh and Haryana also in India).

These thirteen short stories draw the reader in and out of the madness that unfolded across the Land of Seven Rivers and where today, one of those rivers, the Ravi river, flows along the boundary line separating Pakistan 
and India; indeed, this is the region that was the bed rock of the Indus Valley civilization, a region that was, before the Mughal conquest, a Hindu-Buddhist region, also known for its high civilization. By the time of the British Raj conquest, the Mughal Empire was considered to be the world's largest economic and industrial power. Punjab then was religiously diverse yet it was also rooted in deep layers of varied languages, arts, industries and other cultural similarities.

"No Forgiveness Necessary" describes the long and hard day of a young Hindu psychiatrist, who is shot dead at dawn on his bicycle on his way home. In "Belly Button" a school teacher born in 1947 escapes his extremely uneventful and clocklike life on a chance to visit his birthplace and meets with the nurse who delivered him; she says to him "I did deliver you nice and safe. But there was a mob carrying mashaals and yelling like all the fiends of Hell as they rampaged through the lane, barely five feet from where you were born. I was trembling all over when I tied the cord. Normally my handiwork is much better" (p. 51). Mashaals are firetorches, a detail of some importance. In "Partitioning Madness" three psychiatrists discuss what happened in 1947 when only 450 "non-Muslim lunatics" (p.49) were moved from the Pakistani to the Indian side of Punjab; when asked, the medical superintendent explains: "The Lahore hospital reports of 1947 say it was cholera" (p. 53), but, as the conversation goes on, "Would cholera kill just one religion? GOK. GOK? God Only Knows..." (p. 71). In "Sita's Bus", a young woman wakes up a little lost and is told by a nurse "....when the families ask for repatriation, the protocol includes consent for abortion... I have seen hundreds of them. Nobody ever wanted to have a woman back who is pregnant... so the state is doing what the families want. They have allocated a special fund for this" (p. 90).

Maybe this is enough of a detailed review to underscore how boundary line and borders are violent (a reference to Reece Jones' works). Indeed, we, as border scholars, know that they are, yet few of us actually have had physical experience of that violence. What Dr. Kala's profound reflection on the 1947 trauma of partition across the Indus Valley suggests though is that such trauma inhabits the soul of people and borderland communities for generations beyond the creation of the international boundary lines: today, the respective populations of Pakistan's Punjab, and of India's Punjab, Himashal Pradesh and Haryana totals 175 million people.

Another small book that looks at the impact of borders on people is A Prolonged Residency by Aybike Açikel. This is a quick read, where the author reviews and assesses the situation of Syrian refugees in Turkey. In this book we learn about what happens when people move away from home into a foreign land, in particular what has happened in Turkey when refugees from Syria started crossing the border that separates the adjoining countries. We learn that they lose nearly all their rights, that welcoming countries are rarely equipped to welcome newcomers.

The book is organized across five sections: an introduction, three substantive chapters, and a conclusion: chapter one reviews the literatures and definitions for migration, integration, asylum and then the legal frameworks available in Turkey to determine the status of migrant, asylum seekers and refugees. Chapter two, focusing on Syrian refugees, details how those refugees became a crisis, and questions how in Turkey their status was determined. Chapter three is a review of how refugees were, or were not, integrated or integrating in Turkish society, culturally and economically, and also asks whether the way it is done in Germany has any applicability in Turkey. Açikel compares the strength and weaknesses of both policy sets. The comparison of Germany to Turkey usefully gives the reader a sense of what has been done elsewhere; in Germany immigration and refugee policies are not a response to the Syrian crisis and addresses a multitude of aspects required by a comprehensive immigration integration strategy. The author's assessment is that the attempt has not been very successful. The breadth and success of Turkish policies implemented in response to Syrians' mobility into Turkey over the last 10 years remains superficial.

This book's overarching themes include defining migrants, immigrants, asylum seekers, refugees, and with a view to confront international public law and standards. Clearly, countries are not aligning with those standards today but rather implement regulatory systems that address national and local issues at best.

Açikel is ambitious when trying to assess how successful Turkish integration has been; in particular when considering integration from a multi-pronged approach with regards to economic, social, cultural (linguistic), but also particularly religious or ethnic or even legal factors. All in all, it is too ambitious for a small book to systematically document successfully such a complex situation and policy answers.

What we learn, however, that is interesting, is primarily that the migration "open door policy" (p.11) Turkey implemented was initiated as early as 2009 (not 2014-2015); also, we learn that the first Turkish policy answers assumed the issue would be short term and go away (that it did not, we know). We also learn that Syrians were submitted to specific labor laws (the Foreign Employment Law) as late as 2016, that those policies attempted to draw Syrians away from illegal labor status into a registered and legalized lower working status, and with conditions that would fill labor needs without creating a situation of competition or of resentment among the Turkish population. To this day, the system continues to struggle with identifying people, a process that remains particularly difficult. 
In conclusion, the author suggests that while Turkey has developed legislation to adapt policy to unexpected situations, this has led Syrians to leave refugee camps to take jobs with or without registration as illustrated by the continuous limited take on the Turkish health system. It has also led to much increase in violence, in particular against Syrian women, specifically "unregistered women and children" (p. 122) including rapes, forced marriages and domestic violence.

Understanding the impact of refugees into Turkey is only part of the picture and How to deal with refugees? Europe as Continent of Dreams by Gerhard Besier and Katarzyna Stoklosa, is a particularly interesting edited collection because it brings together 20 co-authors of 16 chapters that discuss the complex question of why mobility is on the rise, why people are moving towards the European Union, and what new migrants mean for destination continents and countries, and what kinds of stress, and sometimes trauma, destination countries have to deal with when migrants arrive. The book has three sections; part one focuses on issues arising from increased refugees in the past and today across a few European countries. In the second part, the authors reflect on emerging problems, and inquiries around ethical as well as cultural and religious questions are discussed in the third section.

Johannes Maria Becker and Katharina Becker look at migration triggers around the Mediterranean region and Middle Eastern countries. Their plea is for a European respect of international asylum rights and a limitation on arm sales to countries of origin. Konrad Ott and Moritz Riemann focus on why people leave and seek asylum. They argue that there are three central reasons: a necessary (preventive) escape is one, persecution and escape are a continuum of categories all of which are linked to asylum decisions. In the end, the authors argue new categories and cooperation are necessary to address climate and violent migrations. Then, Katarzyna Stoklosa compares two immigration periods in Hungary; the 1980s is compared to the 2015 crisis. The author argues that a major difference is the religious origins of the migrants and a shift of context: Hungary is now an established member of the European Union and has policies in line with Austria's. Focusing on Sweden and Finland, Jussi Laine and Daniel Rauhut document the frustration and anger that emerges when refugees realize there is a significant gap between their dreams and reality in their country of settlement. Indeed, many end up in overcrowded facilities in the northern regions of Finland or Sweden and live on social assistance, without work because of skills, language, or red tape issues. Using a social networks perspective, Julia Schulze Wessel's paper is particularly interesting because it suggests refugees and migrants change the politics of places and thus issues of democracy and demarcation. Looking at individual perception, Jessica Ortner's chapter is a study of literary works engaging with memorialization and postwar trauma; the returning soldier, the Sudeten German expulsion. In the same vein, the work of Elisabeth Oxfeldt is a literary analysis of class confrontation and discomfort in Scandinavia. Guadalupe Correa-Cabrera and Arthur Sanders Montandon discuss similar issues but in North America; although interesting the chapter is a bit out of place in this book exclusively focused on European experiences.

In part two, Lukas Schmelter suggests that governments are held back because of the lack of engagement and support from people across the European member states. Heike Knortz, looking at migrants into Germany, suggests that they do not have the skills needed to integrate. Documenting the experience in the Arctic regions of the EU, Ekaterina Mikhilova suggests that there is a correlation between migrants' origin and their treatment in Arctic countries. Although overly ambitious, Dawid Bunikowski's chapter deals with data from Sweden, Finland and Denmark and many policy areas. In the end though he suggests that stricter migration rules are needed. Finally, Joni Virkunen suggests that increased inequality in Finland is of most importance to understand support for asylum seekers in Finnish society.

In the last section of the book, Wielant Machleidt and Iris Tatjana Graef-Calliess suggest that a cultural therapeutic gap has to be considered to understand adaptation to countries of destination. Gerhard Besier suggests that there is a little theological common ground between the Islamic, and Christian and Judaic tradition. Finally, the last chapter, by Jussi Laine, suggests that the European Union focus on market security has consequently led to loss of sight of fundamental issues of global mobility.

All in all, this is a rich discussion in which many of the papers are driven by well-informed political views and interesting suggestions of policy implications; the works are highly interdisciplinary and also loosely organized by themes about how the European Union's central and northern member states have struggled in the past and more recently to welcome migrants. The works describe a number of situations in which humanist views dominate but also views that question the political rationales and policy preparedness of the few concerned EU member states.

Focusing on migrants' own stories is possibly the hardest and most demanding, yet most rewarding, of ways to understand why people are mobile or make risky mobility decisions. Twenty years in the making, Mobile Orientation: An Intimate Autoethnography of Migration, Sex Work and Humanitarian Borders by Nicola Mai, is a fabulous book.

Mai details the many stories of lives in the borderlands and transitional spaces of Europe. The resulting work 
is wonderful because it is a very sensitive, and very subtle, ethnographical analysis of the motivations, resources, and identities, available to individuals caught in the webs of great resourcefulness yet much poverty that entangle migrants caught in transition between countries of origin and countries of destination. In the end, Mai is confronting literatures about sex work and human rights, but also about gender and mobilities across borders both physical, psychological, and metaphorical: his approach is critical of humanitarian border and migration perspectives.

The book is organized in nine chapters, an introduction, and a conclusion. An Intimate Autoethnography is a review of methodological discussions. The reader is then drawn into the matter at heart in chapters two, three and four ("Engaging Albanian (and Romanian) Masculinities", "Selling Comidas Rapidas in Seville", and "Boditarian Inscriptions") that are de facto outstandingly rich case studies. Chapter five ("Burning for (Mother) Europe") contextualizes the research in greater detail but is also, in a way, a transition toward much more analytical chapters: six, seven, eight, and nine include "Trafficking and Migration", "Love, Exploitation, and Trafficking", "Interviewing Agents", and "Ethnofictional Counter-Representations" where the author makes his core argument in strides: Mai writes "I have elaborated the concept of 'mobile orientation': socioculturally framed alignments between objects, mobilities and self-representations that frame the emergence of subjectivities. These orientations are mobile, both because they reflect young people's existential aspiration to social and spatial mobility through migration" (p. 192). What is resulting for Mai is a "liquefaction of modes of production, gender roles, authorities, and moralities" (p. 192).

He concludes thus that 'migrant sex workers' pragmatic understandings and experiences of agency on the basis of their 'wants and needs"'(p. 191) is core to understanding both personal and structural transitions in a neoliberal context in which individual construction and agency cannot be dismissed. Obviously controversial, his critical analysis of migrant sex workers should be read by many, in particular those that are concerned by modern forms of trafficking and slavery. His findings are the result of an original methodology, the use of filmmaking, to deconstruct social humanitarian views. In Mai's own words, "I challenge the onto-epistemological distinction between emic (culture-internal) concepts and the etic (cultural external) theories of observers, a distinction that usually characterizes ethnography" ( $p$. 10) to shade new knowledge on the lives, dreams, desires and agency of migrant sex workers in borderlands. In sum, this is a wonderful text and the research findings are counterintuitive; people's awareness, identity formation, and agency are just so well discussed. It is also really interesting from the perspective of borders, both physical and territorial borders, but also individual and internalized-psychological-borders; and the malleability of those personal representations and impacts on people's psyche.

In sum, 2017-18 marks the beginning of a great period for grounded and theoretical research in border studies. This is a rich period of expanding concepts and retheorizing borders and migration, and also of expanding and emerging discussions that link the borders and migration literatures. 